\title{
USING FREE AND OPEN SOURCE SOFTWARE TO TEACH UNIVERSITY GIS COURSES ONLINE: LESSONS LEARNED DURING A PANDEMIC
}

\author{
Sterling Quinn \\ Central Washington University, Department of Geography \\ 400 E University Way, Ellensburg, Washington, USA 98926 \\ sterling.quinn@cwu.edu
}

KEY WORDS: FOSS, higher education, pandemic, online learning, QGIS, PostGIS, GeoDa

\begin{abstract}
:
During the remote learning necessitated by the COVID-19 pandemic, university GIS students did not always have home access to the kinds of software and hardware that they would ordinarily get in their on-campus lab facilities. In this situation, the free and crossplatform nature of FOSS opened the door for some students to continue their GIS education uninterrupted. In this article, I describe how one university allowed students to choose FOSS such as QGIS, PostGIS, and GeoDa as alternatives to proprietary software in upper-division GIS coursework. These were used to teach techniques such as point pattern analysis, visibility analysis, hydrological modeling, proximity surfaces, LISA analysis, process modeling, open data access, and data summation. I share specific software tools, commands, and plugins used to apply these techniques in lab assignments. I discuss how these approaches can form a lasting part of the GIS curriculum beyond the pandemic, and how students can position these FOSS skills as they prepare for the GIS job market.
\end{abstract}

\section{INTRODUCTION}

\subsection{Advantages of FOSS for remote learning}

By its nature, free and open source software (FOSS) allows for much flexibility of deployment, including cross-platform support, minimal hassle with licenses and invoices, and the ability to standardize on a version without vendor-forced upgrades. These benefits have made FOSS attractive to governments, industry, and non-profits (Raymond, 2001; Shaikh and Cornford, 2012). They are especially useful in the online education environment where students use a great variety of home computing environments to complete their lessons and exercises. This article describes how a regional teaching university in the United States used these advantages of FOSS to expand access to geographic information systems (GIS) courses.

\subsection{FOSS and GIS education}

By the early 2010s, desktop-based FOSS GIS options had grown to rival proprietary software in terms of functionality and ease of use (Steiniger and Hunter, 2013), making education in GIS fundamentals easily achievable with FOSS. Although proprietary GIS software skills remain in high demand in the US job market (Hibdon et al., 2019), supplementing a GIS education with FOSS skills offers major advantages for students. Firstly, as students witness the same workflows implemented with multiple tools, they realize that they are learning concepts, not a piece of software. Secondly, FOSS gives them more tools they can use to respond to unexpected situations, such as bugs, crashes, or workflow roadblocks. Thirdly, FOSS experience demonstrates to employers that the student has been able to pick up skills in a variety of technologies, an essential skill in an industry where the tools of the trade are always changing or upgrading. Finally, learning FOSS prepares students for workplace situations where there may be little or no budget for GIS software licenses, at least at the outset of the implementation.
The same benefits of FOSS that allow individual students and professionals to respond to volatility also apply to educational programs. The following case study describes how FOSS helped one university to be more resilient when faced with the unexpected transition to fully online instruction during the COVID-19 pandemic. At the same time, the pandemic forced the acceleration of FOSS-based curriculum development. By providing instructional materials with QGIS, PostGIS, and GeoDa software, faculty were able to continue instruction in their regular topics with minimal adjustment to syllabus documents or schedules.

\section{FOSS IMPLEMENTATION CASE STUDY}

\subsection{Teaching environment}

Central Washington University (CWU) is a state-operated regional teaching university located in Ellensburg, Washington, USA, offering a 4-year undergraduate degree in Geography with a GIScience specialization, as well as a six-course "GIS Certificate" that can supplement any degree program. Although these programs are offered by the Geography department, many students in the GIS courses come from other programs such as Archaeology, Biology, Geology, and Cultural and Environmental Resource Management.

The "core" GIS sequence of courses in these programs consists of three courses in this order: Introduction to GIS and Maps, GIS and Data Management, and GIS Analysis. To build their degree programs, students supplement these core classes with elective coursework in air photo interpretation, remote sensing, computer programming, professional development, and individual research.

The main student GIS lab at CWU consists of thirty 64-bit Windows machines with Intel i5-6500 CPUs and 16 GB of RAM, from which Esri ArcGIS Pro software has traditionally been the primary tool of instruction. Because this lab has all the software pre-installed, adequate hardware for completing GIS 
exercises, 24/7 key card access for students, and a collaborative working environment described by Hickey (2012), most students used it to complete their homework assignments prior to the onset of the pandemic.

\subsection{Early introductions of FOSS into the GIS curriculum}

Aware of the benefits of FOSS for students, CWU had already taken steps in previous years to integrate a taste of FOSS into the GIS curriculum. This was initially done in a piecemeal fashion wherever the software offered unique advantages. For example, QGIS has relatively convenient tools for downloading OpenStreetMap data; therefore, students got exposed to QGIS by trying out these features. Additionally, PostgreSQL and PostGIS provided an interactive environment where students could practice advanced SQL queries, and GeoDa offered linked interactive scatterplot and map views for exploratory spatial data analysis (ESDA) (Anselin et al., 2010). The Geospatial Data Abstraction Library (GDAL) was used to help GIS programming students learn about command line and batch processing environments (Warmerdam, 2008).

FOSS began to take a more deliberate and systematic role in the instruction when the Geography department began offering some GIS course sections online, beginning with Introduction to GIS and Maps in September 2018. During the planning phase for this online section, faculty considered that students could be enrolled from a variety of locations and would not have access to the on-campus lab. The students' home computers might not have the 64-bit Windows operating system required by ArcGIS Pro. Computers with weak graphics cards or RAM might also struggle with this software.

In an effort to widen accessibility, the instructor of the course provided alternate instructions in QGIS for all lab assignments that used desktop GIS. Students could choose between using proprietary software and FOSS. They were encouraged to make this decision based on their computer hardware, career goals, and personal preference.

\subsection{Expanding FOSS GIS instruction during the COVID- 19 pandemic}

The COVID-19 pandemic greatly accelerated the development of online GIS course materials and implementation of FOSS tools in CWU courses. Washington state was one of the first in the country to see outbreaks of COVID-19, and public officials responded rapidly. On 13 March 2020, Washington state governor Jay Inslee announced that all public schools in the state were to close the following week in response to the emerging situation (Furfaro et al., 2020). This occurred near the break between academic quarters, and all the university's GIS courses for the next quarter were immediately forced online with only two weeks of preparation.

This expedited move to remote instruction created a situation where students were attempting to run GIS software in all kinds of computing environments at home. Student computers varied between Macs and PCs, running on anything from old memorystarved laptops to powerful workstations. Internet connection speeds also varied. The university loaned out as many laptops as it could acquire, and a virtual machine server was hastily contracted by the university, but this still left accessibility gaps. There weren't enough laptops to go around, and students reported technical challenges with managing the state of their projects in the virtualized environment.
To enable students to continue with their academic programs and stay on track for graduation, the GIS program director and department chair made the decision to implement more courses with optional QGIS instructions. At the outset of the pandemic this was implemented in the GIS Analysis course. Although this was the most advanced course in the GIS core sequence, it happened to be in the teaching cycle at that period of the academic year. Topics in this course include proximity analysis, terrain analysis, geocoding, interpolation methods, point pattern visualization techniques, and modeling. One of the assignments also used GeoDa for instruction about local indicators of spatial association (LISA).

Later in the year, a GIS and Data Management course was also offered with a QGIS option for the assignments. This course covers coordinate systems, georeferencing, digitizing, data joins, and database design. Additionally, all students in this course installed PostgreSQL and the PostGIS extension on their machines in order to practice with advanced SQL queries. Students reported no major issues with FOSS software installation in their home environments.

Creating assignment instructions with FOSS turned out to be useful, but time-intensive exercise. It opened instructors' eyes to the power of the software, but required diving deeply into some features that previously had been unfamiliar to them. The tools they selected for various instructional workflows are displayed in Table 1. This list is shared with the hope that it will provide a head start to others who are designing GIS curriculum with FOSS.

When trying to get the courses prepared on schedule, it helped to divide the software research work and curriculum development across a team. Faculty, instructional support staff, and graduate student assistants all contributed to the effort of researching tools, updating instructions, recording demonstrational videos, and testing workflows. Figure 1 shows some screen captures from the course exercises.

The efforts to put these courses online have paved the way for the use of FOSS GIS elsewhere in CWU curriculum. For example, graduate students in the Cultural and Environmental Resource Management program are this year receiving a crash course in GIS analysis methods using many of the QGIS procedures that were researched by Geography department faculty during the previous year.

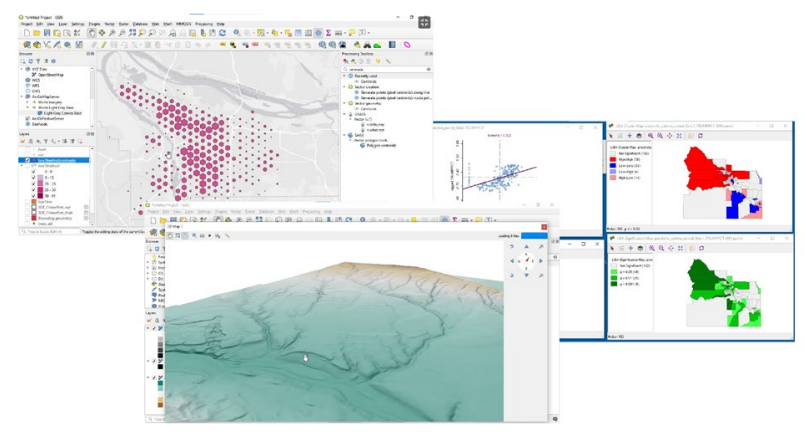

Figure 1. Screen captures from video-led walkthrough exercises. Clockwise from top: Point pattern visualization using aggregation in QGIS, election analysis using Local Moran's I in GeoDa, terrain visualization in QGIS. 


\begin{tabular}{|c|c|c|}
\hline Concept & Software & $\begin{array}{c}\text { Tools, plugins, commands, } \\
\text { and features used in } \\
\text { curriculum }\end{array}$ \\
\hline $\begin{array}{l}\text { Creating maps } \\
\text { and layouts }\end{array}$ & QGIS & $\begin{array}{l}\text { QuickMapServices plugin, } \\
\text { Label toolbar, Layout } \\
\text { Manager }\end{array}$ \\
\hline $\begin{array}{l}\text { Preparing data } \\
\text { for projects }\end{array}$ & QGIS & $\begin{array}{l}\text { Reproject Layer, Assign } \\
\text { Projection, Field Calculator, } \\
\text { Save Selected Features As, } \\
\text { Raster Masking }\end{array}$ \\
\hline Georeferencing & QGIS & Georeferencer plugin \\
\hline $\begin{array}{l}\text { Digitizing and } \\
\text { vector feature } \\
\text { editing }\end{array}$ & QGIS & $\begin{array}{l}\text { Digitizing toolbar, } \\
\text { Advanced Digitizing } \\
\text { toolbar, Snapping toolbar, } \\
\text { Multipart to Singleparts, } \\
\text { Merge Selected Features }\end{array}$ \\
\hline $\begin{array}{l}\text { Simple attribute } \\
\text { queries }\end{array}$ & QGIS & $\begin{array}{l}\text { Select Features by Value, } \\
\text { Select Features by } \\
\text { Expression }\end{array}$ \\
\hline $\begin{array}{l}\text { Spatial queries } \\
\text { and joins }\end{array}$ & QGIS & $\begin{array}{l}\text { Select by Location, Join } \\
\text { Attributes by Location }\end{array}$ \\
\hline $\begin{array}{l}\text { Database } \\
\text { queries with } \\
\text { SQL }\end{array}$ & $\begin{array}{l}\text { PostgreSQL } \\
+ \text { PostGIS }\end{array}$ & $\begin{array}{l}\text { PostGIS Shapefile and DBF } \\
\text { Loader, pgAdmin Query } \\
\text { Tool }\end{array}$ \\
\hline $\begin{array}{l}\text { Proximity } \\
\text { analysis }\end{array}$ & QGIS & $\begin{array}{l}\text { Buffer, Difference, } \\
\text { Proximity (Raster Distance) }\end{array}$ \\
\hline $\begin{array}{l}\text { Terrain } \\
\text { visualization }\end{array}$ & QGIS & $\begin{array}{l}\text { Hillshade, 3D Map View, } \\
\text { Profile Tool plugin, Terrain } \\
\text { Profile }\end{array}$ \\
\hline Terrain analysis & QGIS & Slope, Aspect \\
\hline $\begin{array}{l}\text { Visibility } \\
\text { analysis }\end{array}$ & QGIS & $\begin{array}{l}\text { Visibility Analysis plugin, } \\
\text { Create Viewpoints, } \\
\text { Viewshed }\end{array}$ \\
\hline $\begin{array}{l}\text { Hydrological } \\
\text { analysis }\end{array}$ & QGIS & $\begin{array}{l}\text { Fill Sinks (Wang \& Liu), } \\
\text { Catchment Area, Channel } \\
\text { Network, Maximum Flow } \\
\text { Path Length, Upslope Area }\end{array}$ \\
\hline Geocoding & QGIS & $\begin{array}{l}\text { mmqgis plugin, Geocode } \\
\text { CSV with Web Service, } \\
\text { Geocode from Street Layer }\end{array}$ \\
\hline $\begin{array}{l}\text { Point pattern } \\
\text { visualization }\end{array}$ & QGIS & $\begin{array}{l}\text { Minimum Bounding } \\
\text { Geometry, Standard } \\
\text { Deviational Ellipse plugin, } \\
\text { Create Grid, Count Points } \\
\text { in Polygon, Heatmap } \\
\text { (Kernel Density Estimation) }\end{array}$ \\
\hline $\begin{array}{l}\text { Interpolation } \\
\text { from points to } \\
\text { surfaces }\end{array}$ & $\begin{array}{l}\text { QGIS with } \\
\text { GRASS }\end{array}$ & $\begin{array}{l}\text { v.surf.idw, Ordinary } \\
\text { Kriging, Interpolate (Cubic } \\
\text { Spline) }\end{array}$ \\
\hline Spatial statistics & GeoDa & $\begin{array}{l}\text { Univariate Moran's I, } \\
\text { Univariate Local Moran's I, } \\
\text { Local G* }\end{array}$ \\
\hline $\begin{array}{l}\text { Modeling and } \\
\text { automation }\end{array}$ & QGIS & $\begin{array}{l}\text { Raster Calculator, Zonal } \\
\text { Statistics, Processing } \\
\text { Modeler }\end{array}$ \\
\hline
\end{tabular}

Table 1. FOSS tools used for teaching GIS concepts.

\subsection{Strategies for assisting students with FOSS GIS}

Much of the pre-pandemic GIS instruction at the university occurred in a computer lab with a large screen where students could follow along wall the instructor demonstrated new techniques. Although students seem to appreciate the hands-on nature of this approach, it was easy for them to fall behind or miss a step, even with teaching assistants scurrying around the lab to troubleshoot. During the pandemic, these software demonstrations were presented as a series of prerecorded videos which the students were expected to follow along with at their own pace. The ability to pause and replay sections of the video as many times as needed was lauded by the students in the course evaluation surveys.

Most of the videos were designed to be under 10-minutes in length. They were eventually shared through the "CWU Geography" YouTube channel ${ }^{1}$ in hopes that they would benefit other faculty who are preparing courses, as well as students and professionals that are trying to work their way through GIS procedures. The creation of this channel was also viewed as a way of benefitting the public who funds the university with their taxes.

Many students struggled with the transition to online learning. One of the most important resources lost during the pandemic was the collaborative environment of the university GIS lab where students could seek homework help from each other and their teaching assistants. For students who needed this kind of guidance, we created a Zoom videoconference space for drop-in tutoring. Once again, a team of faculty, instructional support staff, and graduate assistants was crucial toward keeping this space staffed. During the first academic quarter of the pandemic, this "virtual GIS lab" was online 40 hours per week with no appointment needed. It allowed students the opportunity to have cathartic face-to-face interaction with a "real person" during a broad enough set of hours that could accommodate most individual schedules. It became clear in subsequent quarters that this number of hours could be reduced somewhat in response to personnel cuts while still allowing students the ability to get the help they needed.

\section{CHALLENGES AND OPPORTUNITIES}

\subsection{Software usability}

The ability of FOSS to meld together various toolsets and software packages is beneficial for functionality, but can cause challenges with usability. For example, the SAGA, GRASS, and GDAL repositories included in the QGIS Processing toolbox offer a wide range of processing options, but produce confusion when tool searches return multiple results. Although tools may have similar names, they often use different parameter sets and offer varying degrees of documentation. For example, in QGIS, some of the necessary features for the course assignments were in the Processing toolbox by default, while others needed be added via plugins. Still more features were accessible through dropdown menus or toolbar menus.

FOSS developers can assist educators and students by including clear user interface text and supporting documentation. This includes describing which units and coordinate systems are expected, used, or reported by the tool, as well as explaining or suggesting reasonable default values for numerical parameters.

\subsection{Widening the set of GIS skills taught with FOSS}

In the above case study, the priority for instructors was to ensure that students could use required course software from their unique computing environments. Skills that could be https://www.youtube.com/channel/UCnovwU4oaVyRSaAD FyNTOaQ 
practiced in browser-based tools presented a quick way to ensure compatibility, and therefore were lowered in priority for teaching with FOSS. For example, fee-based cloud services from Esri ArcGIS Online were helpful for demonstrating techniques such as network analysis, routing, mobile data collection, and web map creation. (The fees were covered through the university's license, and not paid directly by the students.) These services helped students get accustomed to working with GIS through cloud platforms; however, in the future, tools such as pgRouting, OpenDataKit, GeoServer, and OpenLayers could be used on local computers to demonstrate these functions with FOSS.

\subsection{Student uptake of FOSS GIS}

Most students who possessed the appropriate hardware elected to continue their coursework with the proprietary software, leaving aside the FOSS instructions. Students were not formally polled about their software choices or motives for them; however, it is known that going into the pandemic, many of them were already accustomed to the proprietary software. Attraction toward FOSS might have been quashed by the desire to avoid a new learning curve in the midst of so many other stresses. This is a rational decision that corresponds with Shaikh and Cornford's (2012) suggestion that migration to FOSS should be considered only when there is a real and present need to do so.

Students' choices may also reflect high demands in the United States job market for skills with Esri software (Hibdon et al., 2019). Different countries might have a higher demand for FOSS GIS software skills. For instance, some countries and provinces favor or require FOSS in public computing systems, and these policies have influenced GIS implementations (Lewis, 2010; Quinn, 2020).

Despite the relatively low uptake, the offering of FOSS instruction was able to help students graduate who had no other software alternative. The FOSS was also welcomed by students who were planning to work or volunteer in settings where there might be little budget for GIS software licenses, as well as students who were simply attracted to the open source model.

\subsection{Post-pandemic instruction with FOSS GIS}

As students prepare to return to the traditional classroom following the pandemic, faculty will need to make decisions about how to use FOSS in upcoming face-to-face course offerings. It is relatively easy in an online course to offer students a choice between proprietary software and FOSS instructions; however, in a face-to-face course, instructors often conduct demonstrations in a lab setting where showing two different software options for each workflow might bore or confuse students.

One possible remedy is to demonstrate one piece of software in the lab, while continuing to provide students with links to instructional videos for alternative software. Maintaining multiple sets of instructions over time would require long-term commitment of personnel resources. We have found, however, that creating instructions and demos with FOSS is a useful learning exercise for student assistants, especially those with GIS teaching aspirations.

\section{CONCLUSION}

During the COVID-19 pandemic, FOSS GIS such as QGIS, PostGIS, and GeoDa provided a way that students could complete work from home from various hardware environments using software they could easily get from the Internet. In the described case study, the pandemic accelerated a transition to providing FOSS demonstrations and assignment instructions in various GIS classes from beginning to advanced levels. These materials are expected to benefit both online and face-to-face course offerings in the future. Further study is needed to understand student motives behind choosing FOSS versus proprietary software when given the choice. Learning both FOSS and proprietary software can demonstrate versatility and prepare students to implement GIS in situations across a range of computing environments and budget circumstances.

\section{ACKNOWLEDGEMENTS}

The author would like to thank David Cordner, Sarah Hibdon, and Nicholas Schuelke for their assistance with researching and preparing FOSS GIS teaching materials during the pandemic.

\section{REFERENCES}

Anselin, L., Syabri, I., Kho, Y., 2010. GeoDa: An Introduction to Spatial Data Analysis, in: Fischer, M.M., Getis, A. (Eds.), Handbook of Applied Spatial Analysis: Software Tools, Methods and Applications. Springer, Berlin, Heidelberg, pp. 73-89. doi.org/10.1007/978-3-642-03647-7_5

Furfaro, H., O’Sullivan, J., Morton, N., Bazzaz, D., 13 April 2020. Inslee expands coronavirus K-12 school closure, 250person gathering ban, across Washington. The Seattle Times. https://www.seattletimes.com/education-lab/inslee-announcesall-washington-k-12-schools-to-close-in-an-effort-to-slow-thespread-of-coronavirus/ (1 June 2021).

Hibdon, S., Hickey, R., Cannon, J., 2019. GIS Jobs: Current Industry Expectations. Directions Magazine. https://www.directionsmag.com/article/8795 (1 June 2021).

Hickey, R., 2012. Beyond Class Hours: The GIS Lab as a Center of Geographic Education, in: Albert, D. (Ed.), Geospatial Technologies and Advancing Geographic Decision Making: Issues and Trends. IGI Global, Hershey, Pennsylvania, United States, pp. 46-61. doi.org/10.4018/978-1-4666-02588.ch004

Lewis, J., 2010. Government Open Source Policies. https://opensource.org/files/100416_Open_Source_Policies.pdf (1 June 2021).

Quinn, S., 2020. Free and open source GIS in South America: political inroads and local advocacy. International Journal of Geographical Information Science 34, 464-483. doi.org/10.1080/13658816.2019.1665672

Raymond, E., 2001. The Cathedral and the Bazaar: Musings on Linux and Open Source by an Accidental Revolutionary. O'Reilly Media, Boston, Massachusetts, USA. 
Shaikh, M., Cornford, T., 2012. Strategic drivers of open source software adoption in the public sector: Challenges and opportunities. ECIS 2012 Proceedings, 237. https://aisel.aisnet.org/ecis2012/237 (1 June 2021).

Steiniger, S., Hunter, A.J., 2013. The 2012 free and open source GIS software map-A guide to facilitate research, development, and adoption. Computers, Environment and Urban Systems 39, 136-150. doi.org/10.1016/j.compenvurbsys.2012.10.003

Warmerdam, F., 2008. The Geospatial Data Abstraction Library, in: Hall, G.B., Leahy, M.G. (Eds.), Open Source Approaches in Spatial Data Handling, Advances in Geographic Information Science. Springer, Berlin, Heidelberg, pp. 87-104. doi.org/10.1007/978-3-540-74831-1_5 